\title{
THERMAL "PORTRAIT” OF SPORTSMEN WITH DIFFERENT AEROBIC CAPACITY
}

\author{
E. B. Akimov 2,3 R. S. Andreev,3, V. V. Arkov',, \\ A. A. Kirdin', V. V. Saryanc ${ }^{2}$, V. D. Sonkin ${ }^{1,3}$, \\ A. G. Tonevitsky ${ }^{2}$ \\ ${ }^{1}$ Institute of Developmental Physiology of Russian Academy \\ of Education, Moscow, Russia \\ ${ }^{2}$ All-Russian Research Institute of Physical Culture and Sports, \\ Moscow, Russia \\ ${ }^{3}$ Russian State University of Physical Education, \\ Sport and Tourism, Moscow, Russia
}

\begin{abstract}
Nowadays thermography technique is widely used in clinical and diagnostic procedures. Thermal "portrait" fixed by infra-red thermotracer in rest conditions is characterized by mosaic temperature distribution on skin surface and large individual differences in this pattern. We obtained significant correlations between maximal and average temperature on sportsmen upper body part and important indexes of aerobic capacity - $\mathrm{VO}_{2 \max }$ and anaerobic threshold. We suggest mechanisms responsible for its formation and also propose hypothesis assuming possible role of brown adipose tissue influence on thermal "portrait" forming.
\end{abstract}

Key words: infrared thermography, $\mathrm{VO}_{2 \max }$, anaerobic threshold

\section{INTRODUCTION}

Skin temperature is important marker of physiological state. Its evaluation has a real significance in situations concerned with adaptation to different environmental conditions and muscle activity 
and also reflects heat production intensity which in turns depends on circulatory system recruiting level and sweating rate [8].

Though character of skin temperature distribution in regards to different physiological conditions has great research interest for a long time, technical difficulties did not permit wide using of respective methods. Recently multipoint contact thermometry was a primary method for such type of research but it gave rough estimated values of skin temperature and consequently only an approximate evaluation of organism thermal processes in the whole.

During last years novel infra-red thermovision analysis system devices differing from another one by high adequacy of analysis, possibility of covering more surface area and automatic calculation of average weighted skin temperature in fixed body zone have come into wide application. These techniques permit to use distant and noninvasive method which is absolutely safe and have not any contraindications thus making it suitable for frequently repeating measurements [10]. Thermovision cameras obtain so called thermograms, original specific infra-red "portraits" of all body surface area or separate body segments. These "portraits" show temperature distribution corresponding to thermal state of appointed area.

In rest conditions thermoregulatory system provides temperature maintaining on relatively constant level. At the same time skin temperature of all body surface as on separate body segments can vary in a wide range - from 25.2 to $34^{\circ} \mathrm{C}$ [1]. In elderly and senile persons it is observed skin temperature decrease caused by atherosclerosis and blood vessels infiltration and drop in blood flow related to capillary recruiting deficiency that results in lowering of thermoproduction level [7].

With use of contact-free infra-red thermo tracer it becomes possible to monitor skin temperature dynamics during muscle physical activity with graded load increase and during recovery period. Skin temperature dynamic and its recovery rate after unloading has shown sufficient depending on physical working capacity which some authors evaluate by maximal oxygen uptake level $\left(\mathrm{VO}_{2 \max }\right)$ [9].

Together with large individual differences thermography imaging method can reveal and visualize temperature distribution differences on skin surface area for each individual [4, 12, 13]. Forming mechanism of these differences relies on three basic factors: capillary net structure and its functional activity, sweat glands functioning and its density and metabolic activity of tissues underlying skin layer. In 
combination with environmental conditions all these parameters provide to form a specific individual thermal "portrait" which analyzing in sportsmen of different specializations become main purpose of our research.

\section{MATERIAL AND METHODS}

Forty sportsmen mean age of $23.5 \pm 4.9$, average weight $70 \pm 11.5 \mathrm{~kg}$ and average height of $174 \pm 7 \mathrm{~cm}$ took participation in experimental series. All participants passed through medical examination to confirm their functional suitability for experiment and also signed informal agreement. In accordance with protocol verified by Ethic Committee of All-Russian Research Institute of Physical Culture and Sports, smokers, post operated persons, reconvalescents, individuals with locomotor system disorders or any chronic diseases that could influence on thermoregulation processes were not examined.

All participants were fasted for 2 hours before experimental procedures and had no alcohol receiving 24 hours prior to the evaluation. During 15 minutes on initial phase of experiment each individual was located in isolated chamber for thermal adaptation in muscle rest conditions (air temperature was keeping up to $21-22^{\circ} \mathrm{C}$, air humidity was $45 \%$ ). This part of experiment was designed in so manner to initialize thermoregulation mechanisms activation. After 15 minutes of adaptation back surface thermograms was obtained by NEC TH 9100SL contact-free thermotracer. The camera was maintained at a distance of $3 \mathrm{~m}$ from the subject and at a height of $140 \mathrm{~cm}$ from the floor. Image Processor ${ }^{\circledR}$ Software was used to analyze thermograms. Thermotracer was calibrated every time before single thermograph making.

For a thermal state quantitative analysis all back surface (ABS) area was marked out on each thermogram (Figure 1). Minimal, maximal and average weighted temperatures were evaluated.

For maximal oxygen uptake level $\left(\mathrm{VO}_{2} \max \right)$ evaluation test with graded load increase on treadmill (HP Cosmos) was performed. Initial track velocity was $7 \mathrm{~km} / \mathrm{h}$, then it had been increased on $0.1 \mathrm{~km} / \mathrm{h}$ each $10 \mathrm{~s}$ until the end of exercise performance. Gas analysis was realized with Oxycon Pro (Germany) which was calibrated every time before and after testing. Statistica 6.0 Software was used for statistical data analyzing. 




Figure 1. Back thermogram with marked zone for automatic analysis

\section{RESULTS}

ABS maximal temperature was $33.7 \pm 0.4{ }^{\circ} \mathrm{C}$, average temperature of this zone was $31.6 \pm 0.5^{\circ} \mathrm{C}$ and minimal was $28.9 \pm 1.25^{\circ} \mathrm{C}$ respectively. Average values of oxygen uptake on anaerobic threshold and $\mathrm{VO}_{2 \max }$ were $46.7 \pm 7.2 \mathrm{ml} / \mathrm{min} / \mathrm{kg}$ and $65.5 \pm 8.7 \mathrm{ml} / \mathrm{min} / \mathrm{kg}$ correspondingly. For analysis making all sportsmen were divided into 4 groups in relation to $\mathrm{VO}_{2 \max }$ values (intergroup difference was $10 \mathrm{ml} / \mathrm{min} / \mathrm{kg}$ ). Some single thermograms of sportsmen of each group are presented on Figure 2. 


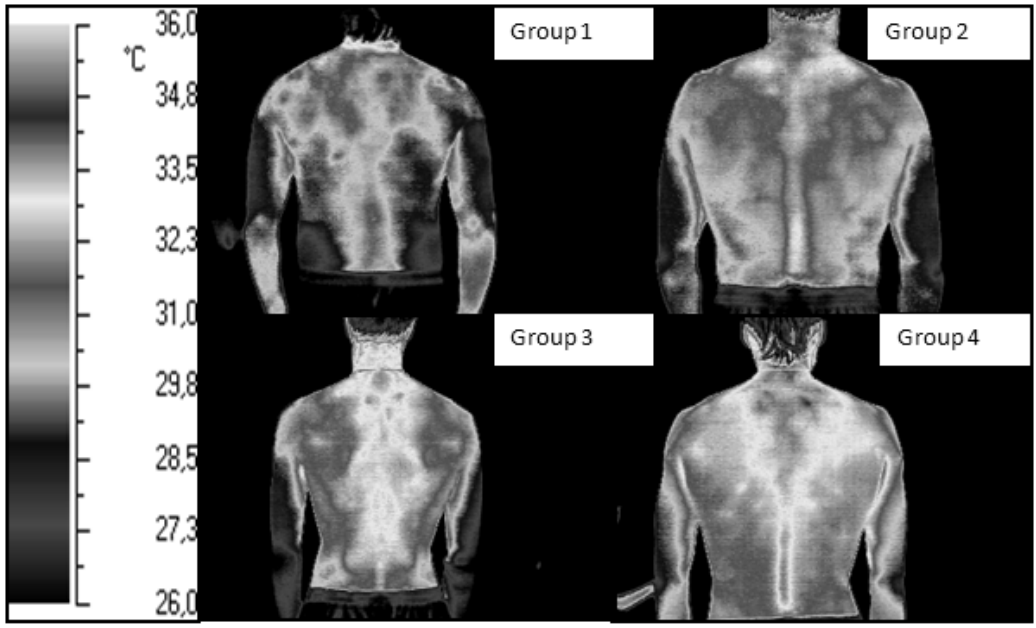

Figure 2. Back thermograms of sportsmen of different groups

We revealed that Group 1 had lowest values and also had lowest minimal, maximal and average ABS temperature comparing with other groups. In other groups increase in $\mathrm{VO}_{2 \max }$ level was associated with rise in ABS temperature (Table 1). At the same time pair groups differences were not significant, whereas differences between Groups 1 and 4 were statistically significant $(\mathrm{p}<0.05)$. Thus there was relation between ABS skin temperature and aerobic capacity. Sample correlation analysis revealed the significant correlation coefficients between $\mathrm{VO}_{2 \max }$ and $\mathrm{ABS}$ average temperature $(\mathrm{r}=0.69), \mathrm{VO}_{2 \max }$ and ABS minimal temperature $(\mathrm{r}=0.61)$ and $\mathrm{VO}_{2 \max }$ and $\mathrm{ABS}$ maximal temperature $(\mathrm{r}=0.51)$ as seen on Figure 3. Furthermore we found correlation between oxygen uptake on anaerobic threshold and ABS average temperature $(\mathrm{r}=0.63)$. 
Table 1. Group values of $\mathrm{ABS}$ temperature and $\mathrm{VO}_{2 \max }$.

\begin{tabular}{|c|c|c|c|c|c|}
\hline & $\begin{array}{c}\text { Group } 1 \\
\mathbf{n}=\mathbf{3}\end{array}$ & $\begin{array}{c}\text { Group } 2 \\
n=6\end{array}$ & $\begin{array}{c}\text { Group } 3 \\
\mathbf{n}=\mathbf{2 0}\end{array}$ & $\begin{array}{c}\text { Group } 4 \\
n=11\end{array}$ \\
\hline \multicolumn{2}{|c|}{$\begin{array}{l}\mathbf{V O}_{2 \max }, \\
\mathrm{ml} / \mathrm{min} / \mathrm{kg}\end{array}$} & $40-50$ & $50-60$ & $60-70$ & $70-90$ \\
\hline \multirow{3}{*}{ ABS } & $\operatorname{Min}^{\circ} \mathrm{C}$ & $26.6 \pm 0.78$ & $28.7 \pm 1.22$ & $28.9 \pm 1.17$ & $29.5 \pm 0.89$ \\
\hline & $\operatorname{Max}^{\circ} \mathrm{C}$ & $33 \pm 0.61$ & $33.5 \pm 0.36$ & $33.7 \pm 0.51$ & $34 \pm 0.28$ \\
\hline & Avr ${ }^{\circ} \mathrm{C}$ & $30.5 \pm 0.5$ & $31.5 \pm 0.34$ & $31.7 \pm 0.43$ & $32 \pm 0.37$ \\
\hline
\end{tabular}


$\diamond$ ABS average temperature

- ABS minimal memperature

$\Delta$ ABS maximal temperature

Figure 3. Correlation between $\mathrm{VO}_{2 \max }$ and $\mathrm{ABS}$ temperature

\section{DISCUSSION}

New options of modern infra-red thermography video technique allow seeing mosaic distribution of temperature on body skin surface of person located in conditions due to moderate activation of thermoregulation processes (comfort humidity, temperature $5-7^{\circ} \mathrm{C}$ below thermoneutral) during 15 minutes period. We confine ourselves with examination of back surface area only as it presents a homogeneous massive in respect to skin layer thickness. In spite of well pronounced 
individual differences it is possible to mark out several zones on back surface that demonstrate increased or decreased temperature as compared with average weighted one in most cases. Almost all examinated persons show increased temperature in cervical region, in thoracic spine area and also in lumbar vertebral area seen as tight stripe shaped zone. On the contrary lateral back regions demonstrate low temperature values differed from most hot spots on skin surface by $7-8{ }^{\circ} \mathrm{C}$. These results are in agreement with other researches using similar methods $[7,9]$.

Nevertheless main question is the cause of mosaic distribution of skin temperature. Only getting the answer we can approach to adequate explanation of obtained results and perhaps thermography imaging will hold its place among diagnostic procedures. Today however the situation in this context is not clear.

There are three processes that can determine local differences in skin regions due to heat dissipation which is essentially fixed by thermal imaging. First process is local blood flow that depends on skin capillaries density (anatomic factor) and vasoconstrictive muscles tonus (vascular tonus autonomic regulation factor). Second process is sweating intensity (sweat glands density and distribution) and its cholinergic activation by sympathetic system. Third process is metabolic activity of tissue lying directly under skin layer controlled by adrenergic stimulation pathways of autonomic nervous system. Our scheme implying seminude persons 15 minutes exposition in room with an ambient temperature of $22{ }^{\circ} \mathrm{C}$ (i.e. notably lower thermoneutral) should initialize sympathetic activation - a typical systematic reaction of thermoregulatory system on cooling. It might result in sweating rate decrease (and heat irradiation decrease as consequence), increase in skin vessels tonus (with the same consequence) and also rising metabolic activity of tissue that is under sympathetic control (and increase in heat irradiation respectively). Contradiction of these reactions does not permit to make unambiguous prognosis of final result in local skin temperature - will it decrease or increase. Correlation coefficients between skin temperature and parameters of aerobic capacity we obtained, not very high but statistically significant reflects with high probability these contradictionary tendencies in organism reactions to moderate short-time cooling. The fact of concordance of aerobic capacity level and such sympathetic dependent parameter as skin temperature undoubtedly presents great interest for discovering mechanisms that determine physical working capacity. 
Early in our research on cosmonauts in conditions of long-term cosmic flight we found strong dependence of aerobic capacity on activity of autonomic nervous system sympathetic branch [11].

It is well known that one of the most metabolically active tissues of human organism is brown adipose tissue [2]. Its activity is under strong sympathetic control [3]. Recent research materials disprove early point of view that brown adipose tissue is inactive in adult people. It is proved that considerable part of adult population has active brown adipose tissue [5]. Its localization is differently presented by authors but more frequently mentioned regions are cervical and supraclavicular areas. Children brown adipose tissue has its main location in cervical and intrascapular zones that is similar with temperature distribution of some individuals in our experiments (see Figure 2, Group 4). Brown adipose tissue contributes to carbohydrate and lipid metabolism during intensive food intake promoting normalization of carbohydrates and lipids in blood. This why converting of white fat in brown to fight obesity is one of the aims of novel genetic engineering investigations [6]. New molecular genetic researches found adipocyte precursors of brown adipose to be much more closer by its characteristics to muscle precursors cells that to white adipose tissue precursors. In that aspect our data suggesting correlation between $\mathrm{VO}_{2 \max }$ and back surface temperature obtain another aspect. Even though it's not enough for concluding that sportsmen with high $\mathrm{VO}_{2 \max }$ values and aerobic capacity have significant amount of brown adipose tissue this proposition seems quite logic and in turns it gives new direction for future investigations.

\section{CONCLUSIONS}

Thermal "portrait" fixed by infra-red thermotracer in conditions of moderate activation of thermoregulation is characterized by mosaic skin temperature distribution on back surface and large individual differences in this pattern. We obtained significant correlations between maximal and average temperature on upper body part of nonclothed sportsmen located in room with normal ambient temperature and parameters of aerobic capacity $-\mathrm{VO}_{2 \max }$ and anaerobic threshold. For physiological explanation of such correlation we suggest mechanisms responsible for its formation and also propose hypothesis assuming possible brown adipose tissue influence on sportsmen 
thermal "portrait" forming in moderate conditions out of thermoneutral zone.

\section{REFERENCES}

1. Agarwal-Kozlowski K., Lange A. C., Beck H. (2009) Contact-free infrared thermography for assessing effects during acupuncture: a randomized, single-blinded, placebo-controlled crossover clinical trial. Anesthesiol. 111: 632-639

2. Cannon B., Nedergaard J. (2004) Brown Adipose Tissue: Function and physiological significance. Physiol. Rev. 84: 277-359

3. Chaudhry A., Granneman J. G. (1999) Differential regulation of functional responses by $\beta$-adrenergic receptor subtypes in brown adipocytes. Am. J. Physiol. Regul. Integr. Comp. Physiol. 277: 147153

4. Clark R. P., Mullan B. J., Pugh C. E. (1977) Skin temperature during running - a study using infra-red color thermography. J. Physiol. 267: $53-62$

5. Cypess A. M., Lehman S., Williams G., Tai I., Rodman D., Goldfine A. B., Kuo F. C., Palmer E. L., Tseng Y. H., Doria A., Kolodny G. M., Kahn C. R. (2009) Identification and importance of brown adipose tissue in adult humans. N. Engl. J. Med. 360: 509-517

6. Farmer S. R. (2008) Molecular determinants of brown adipocyte formation and function. Genes. Dev. 22: 1269-1275

7. Ferreira J. A., Lorena C. S., Mendonc A., Nunes L. A. O., Filho A. C. C., Rebellato J. R., Salvini T. F. (2008) Exercise-associated thermographic changes in young and elderly subjects. Ann. Biomed. Eng. 36: $1420-1427$

8. Kenney W. L., Munce T. A. (2003) Invited review: aging and human temperature regulation. J. Appl. Physiol. 95: 2598 - 2603

9. Merla A., Iodice P., Tangherlini A., Michele G. D., Romualdo S. D., Saggini R., Romani G. L. (2005) Monitoring skin temperature in trained and untrained subjects throughout thermal video. Proceedings of the 27th Annual International Conference EMBS, Shanghai, China. IEEE. 1(4): 1684-1686

10. Ring E. F. J., Ammer K. (2000) The technique of infra red imaging in medicine. Thermol. Int. 10: 7-14

11. Sonkin V. D., Zaitseva V. V., Kozlovskaya I. B., Bayevsky R. M., Tchernikova A. G. (2002) Interrelation of cosmonaut muscle working capacity and autonomous regulation indices during long-term flight. 
// Abstracts of 23rd Annual ISGP Meeting and the 8th TSE Life Sciences Symposium. Stockholm.

12. Torii M., Yamasaki M., Sasaki T., Nakayama H. (1992) Fall in skin temperature of exercising man. Br. J. Sports Med. 26: 29-32

13. Zontak A., Sideman S., Verbitsky O., Beyar R. (1998) Dynamic thermography: Analysis of hand temperature during exercise. Ann. Biomed. Eng. 26: 988-993

\section{Correspondence to:}

Valentine Sonkin

Piatnitskaya ulitsa, dom 76, kvartira 14, Moscow, 115184 Russia

E-mail: sonkin@mail.ru 